\title{
Libraries as Content Producers: How Library Publishing Services Address the Reading Experience
}

\author{
Daniel G. Tracy
}

\begin{abstract}
This study establishes baseline information about the ways library publishing services integrate user studies of their readers, as well as common barriers to doing so. The Library Publishing Coalition defines library publishing as "the set of activities led by college and university libraries to support the creation, dissemination, and curation of scholarly, creative, and/or educational works." This area includes traditional as well as novel publication types. Results suggest that discussions of library publishing underrepresent engagement with readers but that ample room for increased attention remains. Existing reader-related efforts vary widely and may in some cases be happenstance. These efforts also face key barriers in lack of prioritization, lack of expertise, and lack of control of out-of-the-box platforms.
\end{abstract}

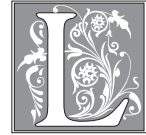

ibrary publishing is a booming area of creation for digital (and often print) collections. Although libraries have long published in areas such as special collections materials and catalogs, library publication of scholarly journals and monographs has become increasingly common. Many library publishing services also take advantage of digital formats to create experimental forms not possible in print: multimedia and digital humanities projects facilitate interaction with content as well as reading. Most of these services publish working papers, dissertations, and other traditionally "gray" literature through institutional repositories, with some focusing exclusively on these publications. All the preceding activities have received increasing attention as a strategic area of library work under the umbrella of "library publishing," leading to the creation of the Library Publishing Coalition in 2013 and subsequent publication of the first Library Publishing Directory in 2014.

This study establishes baseline information about the ways library publishing services integrate user studies of their readers, as well as common barriers to doing so. It particularly focuses on how these services have investigated and acted on the needs, preferences, and behaviors of readers to improve publication design and delivery platforms. Increasingly in libraries, user-centered work on digital interfaces happens under the banner of user experience (UX) research, but library and information science professionals have a long history of engaging in user studies research to understand

Daniel G. Tracy is Library and Information Science and Research Services Librarian and Assistant Professor, University Library, University of Illinois at Urbana-Champaign; e-mail: dtracy@illinois.edu. (C2017 Daniel G. Tracy, Attribution-NonCommercial (http://creativecommons.org/licenses/by-nc/4.0/) CC BY-NC. 
how and why populations use information resources. ${ }^{1}$ While user studies and UX overlap in interesting ways that need further exploration, this article employs the term "user studies" to refer to the broader field of understanding information needs and behavior, and "UX" to refer to the emergent area of user-centered research that informs design of digital interfaces in libraries. For the purposes of distinction, it uses a third term, "reading experience," to refer to the forms of reading engagement produced by publication interfaces designed through these efforts.

Opportunities for using information about readers to better serve their needs and behaviors abound in library publishing. For example, should a journal offer a webonly interface, only downloadable formats (PDF or otherwise), or both? Can the web presence be optimized so that readers can more easily and quickly navigate the table of contents or find specific functions? How can the capacity for annotation in e-books be optimized for reflective academic reading? If the publication is experimental in form - for example, by including mixed media, annotation features for textual or other media, or options for basic text mining of content as a novel reading tool in a digital humanities project - how intuitive are new features to use? If the creator of an experimental interface seeks to create a novel reading experience as a result, is it successful?

As libraries create content that will in turn become collections, it seems natural to draw from the history of user-centered library research, including the increasing focus on UX, to inform publication design. If, as Dan Cohen and Kathleen Fitzpatrick recently noted, "[1]ibraries have the potential to become the crucial nexus for knowledge flows on campus" by producing as well as collecting scholarly output, this publishing activity offers the opportunity not just for library staff to develop new skills but to insist upon the needs of information users (particularly as readers) as fundamental to production of digital scholarship. ${ }^{2}$ Nonetheless, as a recent analysis of library publishing discourse has shown, it has not been readily apparent that libraries see this as a strength they bring to publishing (except, to a certain extent, in a preference for open access publication) or the extent to which they draw on expertise in, or studies of, user needs when producing their own publications. ${ }^{3}$

\section{Background}

Academic libraries have been publishers for over a century. Paul N. Courant and Elisabeth Jones, as well as Ann Okerson and Alex Holzman, have provided recent summaries of the history of library publishing. Libraries were the original homes of university presses, and they have published catalogs as well as editions of primary sources housed in the stacks. If this publishing function was secondary to the primary function of collecting and providing access to works, academic libraries have emphasized publishing as an increasingly important service beginning around the early 1990 s. ${ }^{5}$ Digitization has built on the history of publishing related to special collections, and libraries have collaborated with digital humanists in particular to curate scholarly collections and editions of important work. ${ }^{6}$ Institutional repositories have blurred the line between "access to" and "publication of" electronic theses and dissertations (ETDs) and other traditionally gray literature produced by universities. Publishing of journals, and to a lesser extent monographs (albeit usually in digital formats), increasingly also finds a home in libraries for a variety of reasons, including interest in noncorporate, open access alternatives for journals and books. Perhaps the most overt recognition of publishing as a revitalized library role has emerged from the (re)integration of university presses into academic libraries at many institutions, often as a solution to the economic sustainability of the press. Charles Watkinson notes that as many as 19 university presses now report administratively through their libraries as of 2014 . $^{7}$ 
This revived synergy of publishing and librarianship has garnered increasing attention through a series of reports sponsored by Ithaka (in 2007), the Association of Research Libraries (ARL, in 2007 and 2008), the Institute for Museum and Library Services (IMLS, in 2012), and most recently the Council for Library and Information Resources (CLIR, in 2015). ${ }^{8}$ In one turning point fostering the current momentum, a group of 61 academic libraries formed the Library Publishing Coalition (LPC) in 2013. The organization seeks to provide opportunities to "meet, work together, share information, and confront common issues" around the quickly evolving area of library publishing. ${ }^{9}$ The LPC's subsequent yearly publication of the Library Publishing Directory beginning in 2014 revealed the diversity of academic libraries engaged in mostly scholarly publishing. LPC now has 66 member institutions and had identified 153 institutions with library publishing services between the two editions of the directory released prior to the survey reported here. An additional twelve appear in the newest 2016 directory, for a total of $165 .^{10}$

These publishing programs take a plethora of forms. University presses reporting through libraries may do so in name only or in a more systematically integrated fashion. These university-presses-in-the-library, plus other library publishing services unattached to university presses, provide a range of functions that traditionally signal scholarly publishing, including selection, peer review, workflow management, editing, distribution, and marketing. Other library publishers have embraced a model that Maria Bonn and Mike Furlough refer to as "libraries and publishing," where the library provides researchers with a publication platform (for example, Open Journal Systems or bepress Digital Commons) and some training on its use and related scholarly communications issues. This more restricted set of services leaves selection, editing, and other production activities to scholars. ${ }^{11}$ Still others focus specifically on recognizable digital library activities such as publication of digitized special collections and ETDs or on the challenges of publishing and sustaining unique, often experimental in form, digital humanities projects that require expertise in digital curation as well as publishing. Others look to create a leadership role for libraries in the open education resources movement.

As these examples demonstrate, "publishing" in a library context has been defined broadly in an intentional effort to capture as wide a range of activities as possible. The LPC defines library publishing as "the set of activities led by college and university libraries to support the creation, dissemination, and curation of scholarly, creative, and/or educational works." ${ }^{12}$ Thus, its directory includes many institutions that support deposit of ETDs as their primary or only publishing activity. However, not all libraries and librarians (or scholars and publishers outside libraries) agree that ETDs or other original items deposited in institutional repositories qualify as publications. As Okerson and Holzman note in the recent CLIR report on library publishing, "the boundary between activities that merit the name publishing and less formal and coherent enterprises is fluid and contestable."13 The LPC approach of defining publishing broadly ensures a broad inclusion of activities that may signal growing movements.

This article, like the survey of library publishing activities and financial models reported by Okerson and Holzman, uses the broad LPC definition of library publishing. Throughout this article and in the survey it reports, the term "library publishing services" signifies the full range of activities indicated by the LPC and represented in the directory, regardless of whether they originate in a solo librarian's efforts, a centralized library unit devoted to publishing, or activities scattered across the library. ${ }^{14}$ While some questions pertain to publishing of particular formats, others apply regardless of publishing output. 


\section{Literature Review}

Jingfeng Xia and Isaac Gilman have noted that much of the published research on library publishing has focused on economic and organizational models, with Gilman expanding substantively into legal and ethical concerns. ${ }^{15}$ The high profile examinations of the state of scholarly publishing in general and library publishing in particular-provided by Ithaka, ARL, IMLS, and CLIR - have positioned libraries as publishers, providing a rationale for library publishing based on existing skill sets, mission alignment, the history of publishing in libraries, and other factors. Previous analysis shows that these studies have emphasized a need for libraries to develop staff strengths in working with authors and editors, but it also shows that they have rarely noted how traditional library user studies could provide a substantial, relevant window into the lives of readers. ${ }^{16}$ Libraries' strengths with understanding how patrons use resources, for example, are glimpsed only briefly in an appendix bullet point in the Ithaka report and have not been followed up on. ${ }^{17}$ Likewise, analysis of library publishing service mission statements suggests that readers are rarely seen as core to the purpose-surprisingly, even when considering open access. ${ }^{18}$ Much in line with these analyses, in 2015 the Digital Library Federation (DLF) Assessment Interest Group User Studies Working Group released a white paper noting an absence of research on use and usability of digital collections created by libraries, especially beyond studies of the needs of humanists as a user community. ${ }^{19}$ The report called for more publication in this area, as well as more coordinated user studies on common out-of-the-box platforms in particular.

The role of user studies does appear in individual case studies. Rebecca Kennison, Neni Panourgiá, and Helen Tartar, for example, highlight accessibility and user experience challenges in Columbia University's library publishing service. ${ }^{20}$ Nancy L. Eaton, Bonnie MacEwan, and Peter J. Potter note "knowledge of user behavior and demands" as relevant library values at Pennsylvania State University. ${ }^{21}$ Leila Salisbury and Patrick Alexander have proposed "sharing of user and market data" as a fruitful possibility for library and press collaboration, particularly as it affects "accessibility and navigability" and "understanding user expectations in relation to technology." 22

The research literature on library collections and areas like human-computer interaction offer ample opportunities for engagement in research on library publishing services. A robust literature examines use and perception of academic vendor-supplied e-books and uptake of e-reading devices among students and faculty. These studies highlight the challenges e-books face versus the relative success of electronic journals, in particular due to interface challenges for in-depth scholarly reading. ${ }^{23}$ Work in human-computer interaction has included experiments with a variety of interfaces and reading devices to address challenges in reading digital publications, particularly for academic readers doing the kinds of annotation or extended nonlinear reading often highlighted as a particular challenge in the academic library user studies. ${ }^{24}$ Future work on user needs and behaviors in relation to library publishing platforms could engage with and build from this literature.

More recently, reader-related questions have begun to gain traction as an area for focus in library publishing, albeit largely outside the research literature. Reflecting on a 2015 Summer Seminar on "Access/ibility in Digital Publishing" at West Virginia University, Melanie Schlosser initiated a series of blog posts on accessibility in library publishing. ${ }^{25}$ She notes that the topic has not been prominent in the library publishing discussion to date. Laurie Borchard, Michael Biondo, Stephen Kutay, David Morck, and Andrew Philip Weiss suggest the same absence but provide one recent exception: a study of accessibility of the front and back ends of OJS. They found the front end to meet basic accessibility needs for readers. ${ }^{26}$ Beyond issues for those with disabilities, interface design and related reading issues, which were not particularly prominent at the first Library Publishing Forum, did get scattered mention at the second. 
Another important thread of research features library publishing services as sites for publication of student journals, often but not always student-run as well. As Amy Buckland notes, these journals and related initiatives offer the opportunity for libraries to engage students not just as "consumers" but as "content creators." ${ }^{27}$ This conversation has focused on the specific area of scholarly communications and information literacy due in large part to an ACRL white paper on the topic and a related collection of essays edited by Stephanie Davis-Kahl and Merinda Hensley. ${ }^{28}$ Undergraduate journals have offered ways for librarians to provide instruction on issues such as peer review, author rights, and the economics of information, particularly in regard to open access. However, if undergraduate journals offer an opportunity for pedagogical focus on content creation, UX would be a natural extension of these efforts. Like the lack of focus in the general library publishing literature, the absence of UX and the reading experience from the literature on undergraduate journals could stem from a lack of activity or simply a lack of centrality of UX to the current related discourse.

This article addresses this gap in the literature by examining whether and how library publishing services take into account the needs, preferences, and behaviors of readers when designing (or redesigning) publications. It identifies sources of expertise that library publishers draw from when doing so, as well as barriers that keep them from focusing more on this area. Finally, because of the educational role played by libraries in a wide range of contexts, it examines where and how library publishing services educate their authors and editors about these issues.

\section{Methodology}

This article reports on the findings from a survey developed to identify whether and how library publishing services collect and use information about readers to inform publication design, barriers to doing so, and education of authors and editors on related issues. A colleague with experience leading a library publishing service pretested the survey, and questions were adjusted based on the feedback received. After consultation with the IRB confirmed the study as nonhuman subjects research, an e-mail invitation to participate in the survey went to all of the 153 institutions listed in either the 2014 or 2015 edition of the Library Publishing Directory. The individual for each institution selected to receive the e-mail was the one listed as the contact person in the directory, although library publishing service websites were reviewed beforehand to update contacts where necessary. In a small number of cases where there was no clear point of contact, the invitation went to a library publishing service's general e-mail address. The invitation asked for only one response per institution but noted that the recipient could forward the e-mail to another person in the library more familiar with specifics related to use of reader information in publication design. The survey remained open for four weeks, with two reminders sent over the course of the period. The survey form only recorded responses upon final submission of the survey.

The survey included twenty-six questions, though it posed some only to institutions publishing particular types of material (see appendix A for full survey questionnaire). The first question (Q1) asked the respondent to identify the institution for which he or she was responding. Other questions asked about:

- What sources of information about readers the library publishing service collects and uses for development of particular digital publication types. The publication types included electronic journals, e-books, and experimental forms. Questions listed examples of "experimental forms" as multimedia and digital humanities publications. (Q2-Q13, questions particular to each publication type, were only asked of those indicating that their institution publishes that type.) 
- Where the library publishing service finds the expertise it uses for understanding readers $(\mathrm{Q} 14)$.

- $\quad$ Barriers to further addressing reader needs (Q15-Q20).

- Education of editors and authors about reader needs related to publication design (Q21-Q23).

Questions about frequency of behaviors defined a scope of the most recent two years of activity as the frame of reference. Three open-ended questions at the end of the survey allowed respondents to give specific examples of education of editors and authors, how a publication was developed using information about reader needs, and general feedback on the survey (Q24-26).

While these questions could all be framed in relation to user studies or UX, the survey specified narrower questions to get a more defined sense of actual activities used to understand and design for the needs, preferences, and behaviors of readers. Although in general library user studies focus on consumers or users of information services, it was important to specify questions in relation to readers and the reading experience for library publisher respondents. Library publishing services have often seen their primary users as authors and editors, for whom they must demonstrate value in competition with traditional publishers. These authors and editors are themselves users of back-end interfaces to publishing platforms; therefore, a general survey about "user experience" that did not specify readers could easily be taken to refer to issues related to back-end interfaces for authoring or editorial workflows.

Additional institution-level data were collected separately for all library publishing services receiving the survey to evaluate any variation in response rates. These data included Carnegie classification details for Carnegie Control type (public/private status) and Carnegie Basic type for United States (U.S.) Institutions (non-U.S. institutions were labeled as "International" in these fields). Initially Carnegie Level was included, but it was discarded after discovering that all U.S. institutions in the population fell into the same group of "4-year or above." Carnegie Basic types were grouped into Research, Master's, Baccalaureate, and Special (Faith, Medical, and Technical) institutions during analysis.

Finally, an additional field was added to the data set to indicate whether a library publishing service focused solely on institutional repository deposit for electronic theses and dissertations, technical reports, or other original material. While the survey invitation encouraged participation from all institutions in the directory, and while Q14-Q23 applied across service types, publishing services operating only typical institutional repository services may be less likely to respond to a survey about evaluation of reader needs for publication design. Such services often rely on self-deposit of items, and a reasonable outcome could mean the library does not have significant opportunity for input on UX issues (outside of the basic repository platform). Similarly, the items most likely to receive some guidance on publication design or formats-dissertations, theses, and technical reports - may receive that guidance from units external to the library (such as a graduate college or the writer's department). These conditions of repository services may relate to their status, as noted in the Background section, at the contested, innovative bounds of the expansive definition of publishing used by the LPC.

Basic descriptive statistics were calculated in Excel. ${ }^{29}$ Inferential statistics were not calculated due to the small population. Results are valid only for responding institutions at a particular moment in time.

\section{Results}

\section{Response Rates}

Of 153 library publishing services that received an invitation to participate, 64 completed the survey for a response rate of 41.8 percent. Library publishing services at 
U.S. institutions responded at a greater rate than those at non-U.S. institutions (see table 1). Library publishing services responded at a greater rate from Baccalaureate, Special, and Research institutions, while those at Master's institutions responded at a lower rate (see table 2). Regardless of Carnegie type, library publishing services at private institutions responded at higher rates than public institutions (see table 2). The largest difference in response rate appears when looking at those library publishing services focused on basic institutional repository activities $(18.2 \%)$ versus those with other publishing activities as well (45.8\%) (see table 3$)$.

\section{Information Used to Understand Readers}

Table 4 shows sources of information about reader preferences, needs, or behaviors that library publishing services collected or used in relation to electronic journals (Q3-Q4). Services reported a nearly ubiquitous collection of usage statistics. Fewer services collected information requiring a greater time investment such as usability testing and various types of questionnaires (surveys, interviews, and focus groups), but they almost always put this information to use when collected. Nonetheless, the most frequently used source of information was informal feedback to the publishing service. Similar patterns appear in relation to the information collected and used by library publishing services in relation to e-books (Q7-Q8, see table 5) and experimental forms (Q11-Q12, see table 6). While still reported by a substantial majority, usage statistics were less consistently collected for these types of publication.

\begin{tabular}{|l|c|c|}
\hline \multicolumn{3}{|c|}{ TABLE 1 } \\
\hline & Fesponse Rates by Location of Institution \\
\hline United States $(\mathrm{n}=121)$ & 53 & Response Rate \\
\hline Outside United States $(\mathrm{n}=32)$ & 11 & $43.8 \%$ \\
\hline Total $(\mathrm{n}=153)$ & 64 & $34.4 \%$ \\
\hline
\end{tabular}

TABLE 2

Response Rates by Carnegie Institution Type (U.S. Only)*

\begin{tabular}{|l|c|c|c|}
\hline & Private & Public & Total \\
\hline Baccalaureate & $6 / 11(54.5 \%)$ & N/A & $6 / 11(54.5 \%)$ \\
\hline Master's & $4 / 9(44.4 \%)$ & $2 / 11(18.2 \%)$ & $6 / 20(30 \%)$ \\
\hline Research & $13 / 23(56.5 \%)$ & $26 / 63(41.3 \%)$ & $39 / 86(45.3 \%)$ \\
\hline Special & $2 / 3(66.7 \%)$ & $0 / 1(0 \%)$ & $2 / 4(50 \%)$ \\
\hline Total & $25 / 46(54.3 \%)$ & $28 / 75(37.3 \%)$ & $53 / 121(43.8 \%)$ \\
\hline
\end{tabular}

*Cells show frequency over total $\mathrm{n}$ for that category, followed by rate in parentheses.

\begin{tabular}{|c|c|c|}
\hline \multicolumn{3}{|c|}{$\begin{array}{c}\text { TABLE } 3 \\
\text { Response Rates by Publishing Service Scope* }\end{array}$} \\
\hline & Frequency & Response Rate \\
\hline Basic IR Functions Only $(\mathrm{n}=22)$ & 4 & $18.2 \%$ \\
\hline Activities Beyond Basic IR Functions ( $\mathrm{n}=131$ ) & 60 & $45.8 \%$ \\
\hline
\end{tabular}


In some cases, institutions reported use, but not collection, of a particular type of information, suggesting they may have obtained information about similar populations elsewhere. Therefore, table 4, table 5, and table 6 also report the number of those who used a type of information out of those who collected it specifically. This column in the tables indicates that some institutions may not be making full use of the data they collect. The disparity between usage and collection was greatest for information in the form of transaction logs (automated records of user actions within an interface) for all three publication types.

The survey also asked how often library publishing services used information about readers when designing or redesigning publication formats or interfaces for e-journals (Q5), e-books (Q9), and experimental forms (Q13) in the previous two years. Use of this information was more frequent when designing e-books or publications using

\section{TABLE 4}

\section{Sources of Information Collected and Used by E-Journal Publishers*}

\begin{tabular}{|c|c|c|c|}
\hline & Collect $(n=57)$ & $\begin{array}{c}\text { Rate of Use by } \\
\text { Those Who Collect }\end{array}$ & Rate of Use Overall \\
\hline $\begin{array}{l}\text { Usage Statistics } \\
\text { (downloads/views) }\end{array}$ & $53(93.0 \%)$ & $23 / 53(43.4 \%)$ & $23 / 57(40.4 \%)$ \\
\hline Transaction Logs & $13(22.8 \%)$ & $5 / 13(38.5 \%)$ & $5 / 57(8.8 \%)$ \\
\hline Usability Test Results & $6(10.5 \%)$ & $5 / 6(83.3 \%)$ & $6 / 57(10.5 \%)$ \\
\hline $\begin{array}{l}\text { Surveys, Interviews, or } \\
\text { Focus Groups }\end{array}$ & $6(10.5 \%)$ & $5 / 6(83.3 \%)$ & 9/57 (15.8\%) \\
\hline Informal Feedback & $33(57.9 \%)$ & $26 / 33(78.8 \%)$ & $34 / 57(59.6 \%)$ \\
\hline Other & $6(10.5 \%)$ & $4 / 6(66.7 \%)$ & $13 / 57(22.8 \%)$ \\
\hline \multicolumn{4}{|c|}{$\begin{array}{l}\text { *The "Collect" column indicates those who checked the appropriate box. The next column indicates the } \\
\text { number of those from the "Collect" column who used the information they collected. The final column } \\
\text { indicates all reported use of the type of information: respondents could (and in some cases did) indicate } \\
\text { use of a type of information they did not collect. }\end{array}$} \\
\hline
\end{tabular}

\begin{tabular}{|c|c|c|c|}
\hline \multicolumn{4}{|c|}{$\begin{array}{c}\text { TABLE } 5 \\
\text { Sources of Information Collected and Used by E-book Publishers* }\end{array}$} \\
\hline & $\begin{array}{l}\text { Collect } \\
(n=40)\end{array}$ & $\begin{array}{c}\text { Rate of Use by } \\
\text { Those Who Collect }\end{array}$ & $\begin{array}{l}\text { Rate of Use } \\
\text { Overall }\end{array}$ \\
\hline $\begin{array}{l}\text { Usage Statistics (downloads/ } \\
\text { views) }\end{array}$ & $31(77.5 \%)$ & $19 / 31(61.3 \%)$ & $19 / 40(47.5 \%)$ \\
\hline Transaction Logs & $10(25 \%)$ & $4 / 10(40 \%)$ & $4 / 40(10 \%)$ \\
\hline Usability Test Results & $6(15 \%)$ & $4 / 6(66.7 \%)$ & $5 / 40(12.5 \%)$ \\
\hline $\begin{array}{l}\text { Surveys, Interviews, or } \\
\text { Focus Groups }\end{array}$ & $5(12.5 \%)$ & $5 / 5(100 \%)$ & $9 / 40(22.5 \%)$ \\
\hline Informal Feedback & $25(62.5 \%)$ & $22 / 25(88 \%)$ & $24 / 40(60 \%)$ \\
\hline Other & $6(15 \%)$ & $5 / 6(83.3 \%)$ & $10 / 40(25 \%)$ \\
\hline \multicolumn{4}{|c|}{$\begin{array}{l}\text { *The "Collect" column indicates those who checked the appropriate box. The next column indicates the } \\
\text { number of those from the "Collect" column who used the information they collected. The final column } \\
\text { indicates all reported use of the type of information: respondents could (and in some cases did) indicate } \\
\text { use of a type of information they did not collect. }\end{array}$} \\
\hline
\end{tabular}




\begin{tabular}{|c|c|c|c|}
\hline \multicolumn{4}{|c|}{$\begin{array}{c}\text { TABLE } 6 \\
\text { Sources of Information Collected and Used by Experimental Format } \\
\text { Publishers* }\end{array}$} \\
\hline & $\begin{array}{l}\text { Collect } \\
(n=38)\end{array}$ & $\begin{array}{l}\text { Rate of Use } \\
\text { by Those Who } \\
\text { Collect }\end{array}$ & $\begin{array}{l}\text { Rate of Use } \\
\text { Overall }\end{array}$ \\
\hline $\begin{array}{l}\text { Usage Statistics (downloads/ } \\
\text { views) }\end{array}$ & $28(73.7 \%)$ & $13 / 28(46.4 \%)$ & $13 / 38(34.2 \%)$ \\
\hline Transaction Logs & $9(23.7 \%)$ & $4 / 9(44.4 \%)$ & $4 / 38(10.5 \%)$ \\
\hline Usability Test Results & $9(23.7 \%)$ & $7 / 9(77.8 \%)$ & 7/38 (18.4\%) \\
\hline $\begin{array}{l}\text { Surveys, Interviews, or Focus } \\
\text { Groups }\end{array}$ & $11(28.9 \%)$ & $11 / 11(100 \%)$ & $11 / 38(28.9 \%)$ \\
\hline Informal Feedback & $27(71.1 \%)$ & $24 / 27(88.9 \%)$ & $25 / 38(65.8 \%)$ \\
\hline Other & $4(10.5 \%)$ & $3 / 4(75 \%)$ & $7 / 38(18.4 \%)$ \\
\hline \multicolumn{4}{|c|}{$\begin{array}{l}\text { *The "Collect" column indicates those who checked the appropriate box. The next column indicates } \\
\text { the number of those from the "Collect" column who used the information they collected. The final } \\
\text { column indicates all reported use of the type of information: respondents could (and in some cases } \\
\text { did) indicate use of a type of information they did not collect. }\end{array}$} \\
\hline
\end{tabular}

experimental forms than when designing e-journals, although the difference was not large (see figure 1). Notably, a small number of institutions (three for e-journals, five for e-books) reported never using this information to design or redesign publications, even though they indicated using one of the specific sources of information to develop formats and preferences in responses to previous questions.

\section{Location of Expertise}

The survey asked all library publishing services the remaining questions. When asked where the library publishing service finds expertise used for understanding readers (Q14), 18.8 percent reported not using any such expertise at all. Most, though, had used multiple sources of this expertise, and more than half of the services indicated three or more.

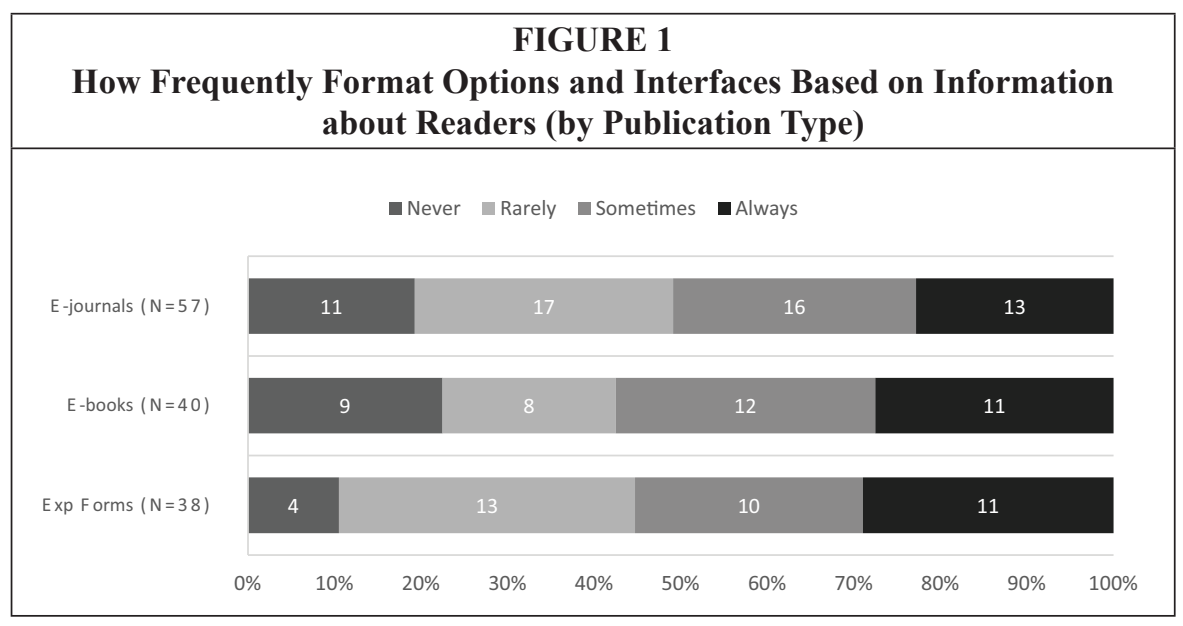


The only location of expertise used by a majority of respondents was relevant research studies $(64.1 \%)$, although almost half consulted with their platform vendor or provider $(48.4 \%)$. If expertise was found at the university, it was more often found in the library, in particular the library publishing unit (43.8\%), than in institutional colleagues outside the library $(18.8 \%)$. Table 7 shows frequencies and percentages for all locations of expertise considered by respondents.

\begin{tabular}{|l|c|c|}
\hline \multicolumn{3}{|c|}{ TABLE 7 } \\
Where Library Publishing Services Find Expertise about Readers (n=64)* \\
\hline Location of Expertise & Frequency & Percent \\
\hline $\begin{array}{l}\text { None: The library publishing service does not make use of this } \\
\text { expertise. }\end{array}$ & 12 & $18.8 \%$ \\
\hline In a library publishing unit, if one exists & 28 & $43.8 \%$ \\
\hline Outside a library publishing unit but inside the library & 20 & $31.3 \%$ \\
\hline Outside the library but within the university & 12 & $18.8 \%$ \\
\hline Platform Vendors or Providers (such as bepress, PKP, and others) & 31 & $48.4 \%$ \\
\hline $\begin{array}{l}\text { Relevant research studies (in other words, Ithaka reports on } \\
\text { reading behavior, library user studies) }\end{array}$ & 41 & $64.1 \%$ \\
\hline $\begin{array}{l}\text { Others outside the university besides platform vendors or } \\
\text { providers (such as colleagues at conferences or elsewhere) }\end{array}$ & 29 & $45.3 \%$ \\
\hline *Respondents chose all options that applied. & \multicolumn{2}{|c|}{} \\
\hline
\end{tabular}

\section{Barriers}

The survey likewise asked all respondents about barriers to further addressing reader needs related to digital publishing formats and interfaces, beyond any current activities (Q15-Q19). Specific options included factors both internal and external to the service (see figure 2). For a majority of library publishing services, policies beyond the service's control at the library, campus, or other level did not pose a barrier or did so only rarely. The obstacle reported most frequently was simply a lack of priority for these activities. Almost half (48.4\%) suggested this posed a regular barrier, with many more saying it sometimes posed a barrier (34.3\%). Still, prioritization was far from a sole cause. All other barriers stymied more than 60 percent of library publishing services sometimes

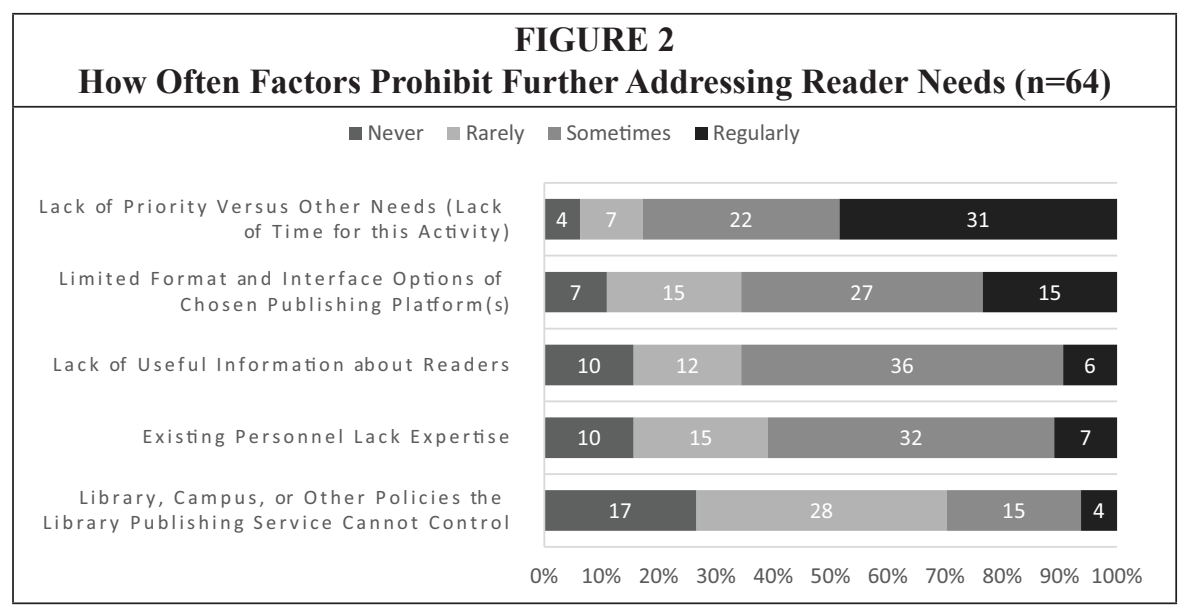


or regularly, including limitations imposed by chosen platforms, a lack of useful information about readers, and a lack of expertise in existing personnel.

When asked to identify the primary barrier to further addressing reader needs (Q20), nearly half identified lack of priority as the most significant barrier for their library publishing service (see table 8). However, slightly more than a quarter of respondents cited the limited format and interface options of their chosen publishing platforms. Responding institutions could also indicate an unlisted barrier as their primary obstacle, and seven $(10.9 \%)$ did so. One of these indicated both prioritization and chosen platform limitations as equally the most significant. The others indicated responses that are closely related to lack of priority versus other needs: lack of interest and lack of community expressed need, limited budget or other resources, and cost.

\begin{tabular}{|l|c|}
\hline \multicolumn{2}{|c|}{ TABLE 8} \\
Primary Limiting Factor When Addressing Reader Needs (n=64) \\
\hline Limited format and interface options of chosen publishing platform(s) & $17(26.6 \%)$ \\
\hline Lack of useful information about readers & $3(4.7 \%)$ \\
\hline Existing personnel lack expertise & $3(4.7 \%)$ \\
\hline Lack of priority versus other needs (lack of time for this activity) & $31(48.4 \%)$ \\
\hline Library, campus, or other policies the library publishing service cannot control & $3(4.7 \%)$ \\
\hline Other & $7(10.9 \%)$ \\
\hline
\end{tabular}

\section{Education of Authors and Editors}

All respondents also provided information about the frequency with which their services educated authors and editors about reader-related issues in their publications (Q21-Q23). A plurality reported sometimes educating authors and editors about these issues for each type-a majority for each type said sometimes or always (see figure 3 ). However, services reported educating faculty and other nonstudent editors more frequently than the other groups.

The question about education did not define "education" to allow for a range of informal and formal educational settings. To get a sense of the range of specific

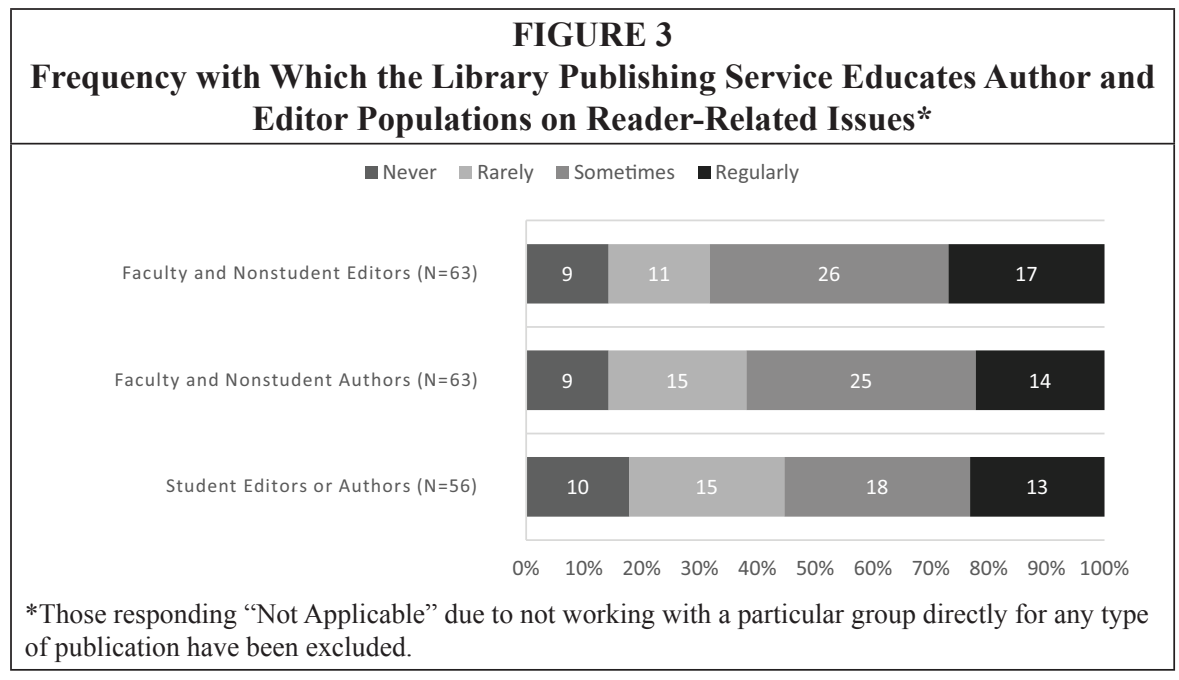


activities, one open-ended question asked respondents to describe an example of how their library publishing service educated authors and editors (Q24). Thirty-one institutions responded to the prompt. Most did not indicate a specific population, but six mentioned working with students, and five indicated working with faculty or other nonstudent authors and editors on these issues. Educational approaches included one-on-one consultations or advice, optional or required workshops and training sessions, class visits, checklists or web guides, and working alongside authors and editors in more sustained engagements on these issues. Most responses included multiple approaches. Specific topics included accessibility, responsive design, format and interface options, open access, metadata and search optimization, webpage load time, and layout/page design. None of these topics, however, emerged as particularly common.

\section{Variety of Activities}

To get a better sense of how library publishing services use information about readers in publication design, another open-ended question asked for a brief description of the most recent example of how they did so (Q25). Twenty-four institutions responded to the prompt. Grounded analysis of themes revealed a wide variety of activities that addressed reader needs, behaviors, and preferences, with several repeated themes. The most common responses had to do with improvements to discovery of material (such as through search engine optimization) and the addition of new digital formats to broaden reading options. Two responses highlighted the creation of new print format options for those preferring print, and two others mentioned digitizing materials or transitioning to digital production. Several also indicated improvements to the journal's interface or functionality. A list of themes can be found in table 9 .

\begin{tabular}{|l|c|}
\hline \multicolumn{2}{|c|}{ TABLE 9 } \\
Themes of How Library Publishing Services Incorporated Reader Issues into \\
Development or Improvement of Digital Publications \\
\hline Added Digital Formats & 5 \\
\hline Search Optimization/Discovery & 5 \\
\hline Interface/Functionality Improvement & 4 \\
\hline Integration of Altmetrics & 2 \\
\hline Added Print on Demand & 2 \\
\hline Digitization/Transition to Digital Format & 2 \\
\hline Usability & 2 \\
\hline General Assessment of Needs & 2 \\
\hline Access & 2 \\
\hline Platform Selection & 2 \\
\hline Guidance/Education of Creators of a Project & 2 \\
\hline Accessibility & 1 \\
\hline Platform Improvement & 1 \\
\hline Other/General Design Issues & 6 \\
\hline
\end{tabular}




\section{Discussion}

Response rates show that institutions with ETD or repository-focused library publishing services responded to the survey at a much lower rate than other institutions. United States Baccalaureate and Master's institutions and International institutions had higher rates of these limited publishing services, so the lower responses for Master's and International institutions may be related to their focus. Reasons for the lack of response could vary, though, including a lack of time at smaller institutions or language barriers for International institutions (although all invited had submitted a directory entry in English). However, these institutions may not have felt the topic of the survey related to their services despite the e-mail invitation encouraging participation regardless of activity. Regardless, the responses overrepresent library publishing services that publish at least some electronic journals, e-books, or experimental forms -in other words, those that have most expanded into traditional scholarly publishing or have taken on experimental publishing projects. Therefore, it is not surprising that the vast majority of respondents $(89.1 \%)$ reported publishing electronic journals, or that a majority of respondents indicated publication of e-books (62.5\%) or experimental forms $(59.4 \%)$. The following results should be read with this imbalanced response in mind.

Responses indicate that engagement with reader needs, preferences, and behaviors in format options and interface design is more prevalent among library publishing services than has been evident in the practitioner literature to date. Around half of services that publish electronic journals, e-books, and experimental forms report using such information "Sometimes" or "Always" in their publication design, with slightly higher rates for e-books and experimental forms. The difference, though small, may derive from the much earlier move of journals to electronic format (providing a feeling that they are a solved problem) and availability of more out-of-the-box electronic journal publishing platforms. As noted in the literature review, e-book design still faces broad challenges as publishers experiment with interfaces to allow a better reading experience with features such as annotation and support for extended nonlinear reading more common in academic reading. Experimental forms such as digital humanities and multimedia projects have unique design considerations that offer opportunities for user studies, such as novel ways to interact with content or how best to integrate mixed media.

While library publishing services reported more engagement with reader needs than expected, other evidence in the survey indicates that much of this activity is incidental and that there are missed opportunities. Library publishing services reported collection of a range of information types about reader needs, preferences, and behaviors, but collection was uneven. Much of the collected data goes unused. Although nearly all e-journal services and three quarters of book services collected usage statistics (total downloads or views of a publication), less than half of services collecting these data actually used it to inform publication design or format options. These services collect transaction logs less often, but similarly the collected information is used to feed back into design in less than half of those cases. In fact, transaction logs had the biggest gap between collection and use for all publication types. Although transaction logs often require labor-intensive analysis to decipher and code the data included, this is an area of missed opportunity since these records usually include richer details of reader behavior. These can include paths of navigation, time spent reading particular content, or other features depending on the logs and overall system design. Not surprisingly, given the time-intensive nature of data collection, services almost always use collected information from usability tests and from surveys, interviews, and focus groups. However, collection of these types of data only occurs at a handful of institutions. The only source of information both collected and used by the majority of institutions was 
informal feedback, indicating a lack of systematic engagement overall.

In some cases, an institution reported use, but not collection, of a type of information. Some respondents may have interpreted the term "collect" as systematic or long-term collection, although the high reported rate of collection of informal feedback cuts against this explanation. It could also be the case that some services are using information collected by others, such as that reported in published research, which other parts of the survey suggest.

The survey identifies several common barriers that prevent library publishing services from using information about readers to improve publication design, or that limit action even for those that do. Prioritization, given time constraints, may be the biggest barrier, and this challenge may be understood in the context of library publishing services investing significant time and resources in establishing operations: developing skills in new areas, working out an economic and organizational model, and developing outreach practices for working with researchers in their authorial and editorial roles may simply be absorbing available attention and resources.

Library publishing services also face a major external barrier to responding to reader needs due to inherent limitations that come with out-of-the-box platforms. These platforms involve a trade-off: they allow quicker start-up of services that do not need to reinvent publication technologies or invest in programming time for significant customization, particularly for journals. However, adoption of these platforms also means limited control over design (or anything else) beyond standard layout and setting options such as CSS themes, and an inability to foster experimental formats that may not fit. The fact that almost half of services find some expertise about readers from platform vendors or providers suggests they can get some assistance with these platforms. Still, one respondent wrote, in the open response field at the end of the survey, "[y]ou hit the nail on the head with the item about the limitations of existing publishing platforms." This respondent went on to highlight the challenge of trying to balance the more easily achieved sustainability of standard platforms against projects that need more flexible, innovative solutions. Occasionally this expertise can run the other way, with the library contributing back to the platform provider: one respondent, at an institution that partners on Open Journals Systems (OJS) development, noted, "we routinely contribute bug fixes to the OJS code base, usually based on userreported problems." With increasing reliance of libraries on these shared platforms, one important way forward for UX work in library publishing may be to strengthen feedback mechanisms and communities so that libraries can contribute to the overall improvement of platforms without taking on the sole responsibility.

Many libraries, though, simply lack the expertise to collaborate in this fashion. While very few identified lack of expertise as their primary challenge, 60.9 percent said a lack of expertise about readers acted as a barrier to improving design "Sometimes" or "Always." Although most respondents identified multiple sources of expertise, further analysis shows that 28 services (43.8\%) did not have any expertise for understanding readers in the library (inside or outside a publishing unit), and nearly all of those (26, $40.6 \%$ of respondents) lack that expertise even when looking to the university as a whole. In other words, most expertise is external-from vendors, colleagues at other institutions, or previous studies - and these library publishing services have little capacity to assess reader needs directly.

The lack of expertise, then, may pose a more significant challenge than appears in responses indicating the top barrier to addressing needs of readers. Lack of expertise is related to prioritization, with which it may have a circular relationship. If understanding of readers in design is not prioritized, it is unlikely that expertise will be sought or hired; if no one in this service has the expertise, readers may not have the advocate 
they need to become a priority. It is unclear whether individual library publishing services reporting no expertise available at their institution simply have not seen and thus have not taken advantage of expertise that does exist (such as UX librarians or researchers), or whether they truly lack it.

Library publishing services report a wide variety of educational efforts related to UX, although without much consistency in degree or kind of engagement with student and nonstudent authors and editors. The range of efforts makes sense due to the different services offered across institutions. Moreover, the type of educational efforts called for may vary depending on the particular area in question. Accessibility standards may call for specific prescribed approaches, and thus education might focus on the purpose for them and what they are, whereas broader interface and functionality decisions may require education of authors and editors on implications of different options so that they can make a final determination.

Student authors and editors receive education in this area less consistently than faculty or other nonstudent authors and editors, although a small majority of services still report education of this group. This lower level of activity in work with students may surprise, given that a general purpose of these student publications is instructional. However, design issues may not have been as clearly tied to the instructional purpose, and students may have less of a say in the final design due to faculty oversight. Even in cases where instruction occurs, this survey does not reveal its depth. That half of those working with students do address these issues "Sometimes" or "Always," though, suggests that literature on the intersection of scholarly communications and information literacy may have missed an area of synergy in the use of undergraduate journals to teach issues about content creation.

\section{Conclusion}

Library publishing services have sought to act on information about the UX of readers more than currently represented in the literature on library publishing. However, this work is by no means pervasive. Existing efforts may be incidentally rather than intentionally achieved, and some library publishing services miss opportunities for action. The fact that only a handful of institutions do any usability testing of their platforms and interfaces for e-journals, e-books, or experimental forms is of particular concern. Library publishing services do not always make use of information about readers that they have, facing challenges that make it hard to prioritize needs, preferences, and behaviors of readers in publication design.

Library publishing services may face additional challenges not explored in the survey that influence the lack of priority they have placed on UX. As libraries turn to serve the needs of users in their authorial and editorial roles rather than their roles as readers, production-oriented tasks may seem the most pressing. Back-end UX issues with workflow tools for authors may compete with front-end UX for attention of developers. Long-term preservation may also draw available attention. Finally, the focus on open access and how best to implement it may unintentionally obscure issues readers face once they do access a work.

A key limitation of this study and an area for further work is the lack of responses from library publishing services listed in the directory that focus solely on institutional repository services for electronic theses and dissertations, technical reports, or other original deposits. As a result, the analysis in this article mostly describes practice at library publishing services with the most traditional publishing outputs. However, as noted above, the 2015 DLF assessment white paper that reviewed literature in the area of digital libraries, including institutional repositories, suggests a similar lack of user studies. As with the lack of focus on user studies noted in this article's literature 
review, it could be that some work is being done but not reported to the broader community in the published literature. A similar survey to this one, though adapted to the specific audience, could be directed toward institutional repository managers. This would have the added benefit of capturing the many institutional repositories that have not been represented in the library publishing directory at all, which far outnumber those the directory does list. ${ }^{30}$ A comparative study including the broader universe of university presses beyond those reporting to libraries would likewise offer comparison to more traditional publishers also situated in the university. A study could also go further to include other academic publishers outside universities, including commercial entities.

More important, this article points to the ample opportunity for growth in user studies generally, and UX work specifically, across several dimensions of the research and practice of library publishing services. Undergraduate journal programs, often used to educate students on scholarly communication issues, could likewise serve as the site of education about how interface and design decisions impact readers. The dearth of usability studies in existing practice needs attention. Engagement with the research on library e-book collections and human-computer interaction could help library publishing services provide solutions to e-book interface problems faced by academic readers requiring annotation functionality and an extended nonlinear reading experience. Indeed, the emphasis on open access in library publishing services offers the opportunity to start ahead of the curve; issues related to digital rights management create some of the more significant usability and reading experience problems in vendor-provided collections as reported in existing user studies.

Whether or not individual libraries consider their digital collections to be publishing efforts, the DLF white paper's emphasis on a need for further shared user studies research on digital collections interfaces resonates here. In particular, the call for a wider community of research that feeds back into shared platforms speaks to the limitations that respondents to the present survey face in relation to out-of-the-box publishing solutions. Research on vendor-provided electronic collections and discovery layers has provided a way for libraries to share information about user issues with each other and those vendors, and there is a need to do this for library publishing solutions as well. Libraries are creating new materials for digital collections as they publish, and librarians should not let these materials produced at home go without the same level of examination given to other resources.

One virtue of library involvement in publishing sometimes cited is that, in the words of Joyce L. Ogburn, "Librarians are embracing their roles in the entire cycle of knowledge creation, dissemination, access, use, and preservation." ${ }^{31}$ A benefit of increased library involvement in the full information cycle should be that we find ways for traditional library strengths related to the moments of consumption in that cycle to inform and be informed by increasing library expertise in production. Investigation into how patron populations use information resources has long driven service development in libraries, and there is incredible potential for this to be the case for new production-driven services in scholarly communications and publishing that will create at least some portion of tomorrow's collections.

\section{Acknowledgements}

Thank you to Zach Claybaugh for assistance with collection of supplementary data for this project. Thanks to Maria Bonn for pretesting the survey and reading a partial draft. Colleagues Suzanne Chapman, Cindy Ingold, Aaron McCollough, Heather Simmons, and Mara Thacker also provided much appreciated feedback or advice on drafts. 


\section{Appendix A. Survey Questions}

\section{Survey Intro Text}

Thank you for participating in this survey of library publishing services. The survey seeks to gather basic data about how and to what extent library publishing services address the needs of readers of their digital publications, and barriers to doing so. Your institution has been invited to participate because it has appeared in either the 2014 or 2015 Library Publishing Directory.

All questions relate to the activities of the library publishing service as a whole, and you are asked to respond on behalf of your institution. If you are not the best person in your library publishing service to answer these questions, please exit the survey and forward the original e-mail to the person in your library who would be appropriate. Only one person from each institution should respond.

To indicate agreement to participate, please enter the name of your institution. Responses will be linked to the institution for analysis of broad trends by type of institution but not to you as an individual.

Any questions or feedback about this survey can be sent to Dan Tracy (dtracy@illinois.edu).

Q1: Name of institution (required)

Q2:_Does your institution's library publishing service publish (or support publication of) electronic journals? (required) Yes

_ No [Skips to Q6]

Q3/Q4: For electronic journals, what sources of information regarding reader preferences, needs, or behaviors does the library publishing service collect, and which does it use for developing publication format options and interfaces? [check all that apply]

Collect. (Q3) Use for Developing Formats and Interfaces (Q4)

Usage statistics (downloads/views)
Transaction logs
Usability test results
Surveys, interviews, or focus groups
Informal feedback
Other

Q5: Considering the past two years up through current practice, when format options and interfaces for electronic journals are designed or redesigned, this is done using information about reader needs, preferences, and/or behaviors [choose one]:

Never

Rarely

Sometimes

Always 
Q6: Does your institution's library publishing service publish (or support publication of) electronic books (e-books)? (required)

Y_ No [Skips to Q10]

Q7/Q8: For electronic books (e-books), what sources of information regarding reader preferences, needs, or behaviors does the library publishing service collect, and which does it use for developing publication format options and interfaces? [check all that apply]

Collect. (Q7) Use for Developing Formats and Interfaces (Q8)

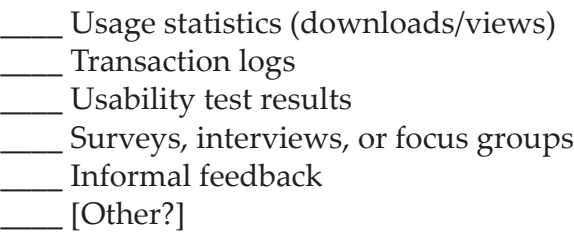

Q9: Considering the past two years up through current practice, when format options and interfaces for electronic books (e-books) are designed or redesigned, this is done using information about reader needs, preferences, and/or behaviors [choose one]:

Never
Rarely
Sometimes
Always

Q10: *Does your institution's library publishing service publish (or support publication of) digital experimental forms (such as nontraditional digital humanities publications, multimedia projects)?

Yes

No No [Sips next page]

Q11/Q12: For digital experimental forms (such as nontraditional digital humanities publications, multimedia projects), what sources of information regarding reader preferences, needs, or behaviors does the library publishing service collect, and which does it use for developing publication format options and interfaces? [check all that apply]

Collect (Q11) Use for Developing Formats and Interfaces (Q12)

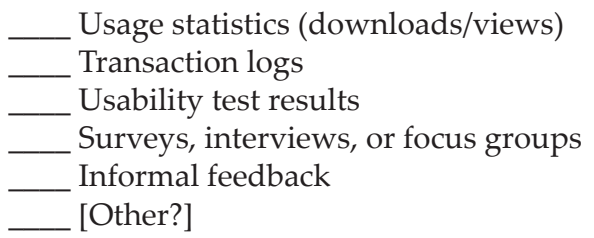

Q13: Considering the past two years up through current practice, when format options and interfaces for experimental forms (such as nontraditional digital humanities publications, multimedia projects) are designed or redesigned, this is done using information about reader needs, preferences, and/or behaviors [choose one]:

Never 
Rarely
Sometimes
Always

Q14: Considering the past two years up through current practice, where does the institution's library publishing service find expertise it uses for understanding readers? [Please check all that apply.]

None: The library publishing service does not make use of this expertise. In a library publishing unit, if one exists Outside a library publishing unit but inside the library Outside the library but within the university Platform vendors or providers (such as bepress, PKP, and the like) Relevant research studies (in other words, Ithaka reports on reading behavior, library user studies)

Others outside the university besides platform vendors or providers (such as colleagues at conferences or elsewhere)

Q15-Q19: Considering the past two years up through current practice, how often do the following prohibit the library publishing service from further addressing reader needs related to any digital publication formats and interfaces? (Choices: Never, Rarely, Sometimes, Frequently)

Q15: Limited format and interface options of chosen publishing platform(s)

Q16: Lack of useful information about readers

Q17: Existing personnel lack expertise

Q18: Lack of priority versus other needs (lack of time for this activity)

Q19: Library, campus, or other policies the library publishing service cannot control

Q20: What is currently the primary limiting factor keeping the library publishing service from further addressing reader needs related to any digital publication formats and interfaces? [choose one]

Limited format and interface options of chosen publishing platform(s) Lack of useful information about readers Existing personnel lack expertise Lack of priority versus other needs (lack of time for this activity) Library, campus, or other policies the library publishing service cannot control Other [please specify]

Q21: Library publishing staff educate faculty or other nonstudent editors on readerrelated issues such as accessibility, format preferences, or interface design as related to their digital publications: [choose best option]

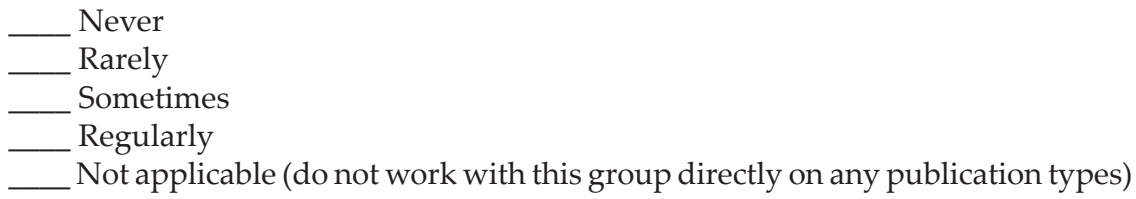

Q22: Library publishing staff educate faculty or other nonstudent authors on readerrelated issues such as accessibility, format preferences, or interface design as related to their digital publications: 


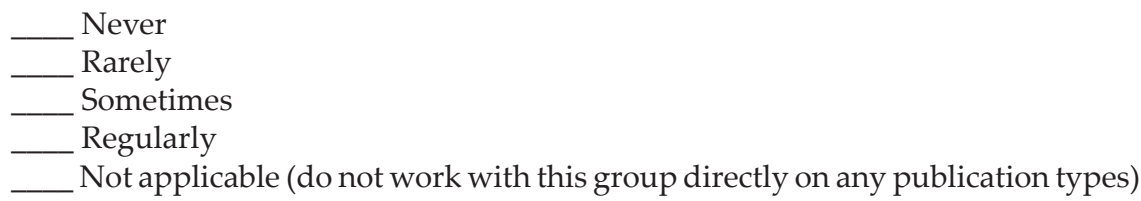

Q23: Library publishing staff educate students editing or authoring graduate or undergraduate student publications on reader-related issues such as accessibility, format preferences, or interface design as related to their digital publications:

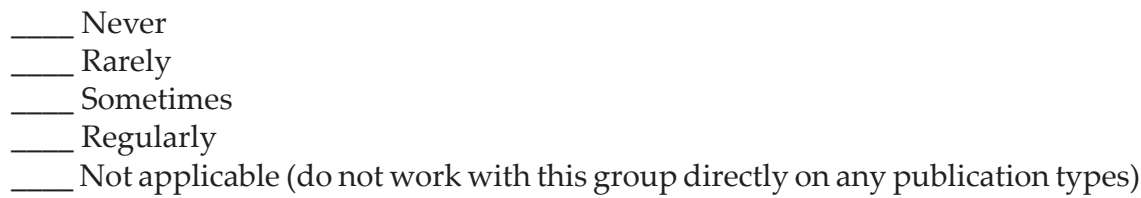

Q24: If the library publishing service does so, please give an example of how staff educate any of the above types of users about reader-related issues such as accessibility, format preferences, or interface design as related to their publications. [open ended]

Q25: Please describe the most recent example, if one exists, of how the library publishing service has developed or improved a digital publication or digital publishing platform with consideration of information about reader preferences, needs, and behaviors. [open ended]

Q26: If you have any other comments related to the library publishing service's activities in the areas covered by this survey, or the survey itself, please include those below. [open ended]

\section{Notes}

1. User studies in library and information science, in both the practitioner and nonpractitioner literature, is so pervasive that it can be observed in most new issues of any research journal in the field. Relevant connections, particularly to user studies in the context of e-book collections, are highlighted in the literature review. For overviews of how UX is being incorporated into libraries, its emergence, and approaches to UX, see: Robert Fox and Ameet Doshi, SPEC Kit 332: Library User Experience (Washington, D.C.: Association of Research Libraries, 2011); Jean E. Mclaughlin, "Focus on User Experience: Moving from a Library-Centric Point of View," Internet Reference Services Quarterly 20, no. 1/2 (2015): 33-60, http://dx.doi.org/10.1080/10875301.2015.1064 845; Aaron Schmidt and Amanda Etches, Useful, Usable, Desirable: Applying User Experience Design to Your Library (Chicago: American Library Association, 2014). The new practitioner journal for libraries and UX is Weave: Journal of Library User Experience (available online at http://weaveux. org/ [accessed 13 December 2016]).

2. Dan Cohen and Kathleen Fitzpatrick, "Foreword," in Getting the Word Out: Academic Libraries as Scholarly Publishers, eds. Maria Bonn and Mike Furlough (Chicago: ACRL, 2015), vii-x, viii.

3. Daniel G. Tracy, "The Users of Library Publishing Services: Readers and Access Beyond Open," Journal of Electronic Publishing 18 (Summer 2015), doi:http://dx.doi. org/10.3998/3336451.0018.303.

4. Paul N. Courant and Elisabeth A. Jones, "Scholarly Publishing as an Economic Public Good," in Bonn and Furlough (2015); Ann Okerson and Alex Holzman, The Once and Future Publishing Library (Washington, D.C.: Council on Library and Information Resources, 2015), available online at www.clir.org/pubs/reports/pub166 [accessed 6 August 2015].

5. Okerson and Holzman, The Once and Future Publishing Library, 4.

6. For a good introduction to academic library roles in digital humanities with specific discussion of both digital editions and digital collections, see Stewart Varner and Patricia Hswe, 
“Digital Humanities in Libraries," American Libraries (Jan/Feb 2016), available online at http:// americanlibrariesmagazine.org/2016/01/04/special-report-digital-humanities-libraries/ [accessed 13 December 2016]. Due to issues surrounding publication of that article, interested readers should examine the postprint and related documents available through Pennsylvania State University's ScholarSphere for a fuller understanding of its context, available online at https://scholarsphere. psu.edu/files/9c67wm855 [accessed 13 December 2016]. For a more in-depth look at collaborations on DH publications based in text encoding, see Harriett E. Green, "Facilitating Communities of Practice in Digital Humanities: Librarian Collaborations for Research and Training in Text Encoding," Library Quarterly 84, no. 2 (2014): 219-34.

7. Charles Watkinson, "From Collaboration to Integration: University Presses and Libraries," in Bonn and Furlough (2015): 83-112.

8. Laura Brown, Rebecca Griffiths, Matthew Rascoff, and Kevin Guthrie, University Publishing in a Digital Age (New York: Ithaka, 2007), available online at www.sr.ithaka.org/researchpublications/university-publishing-digital-age [accessed 2 September 2015]; Association of Research Libraries, ARL: A Bimonthly Report on Research Library Issues and Actions from ARL, CNI, and SPARC 252/253 (2007); Karla L. Hahn, Research Library Publishing Services: New Options for University Publishing (Washington, D.C.: ARL, 2008); James L. Mullins, Catherine Murray-Rust, Joyce L. Ogburn, Raym Crow, and October Ivins, Library Publishing Services: Strategies for Success: Final Research Report (Washington, D.C.: SPARC, 2012), available online at http://docs.lib.purdue. edu/purduepress_ebooks/24/ [accessed 2 September 2015].

9. Library Publishing Coalition, "Background," available online at www.librarypublishing. org/about-us/background [accessed 2 September 2015].

10. The 2016 directory, released after this survey, identified twelve additional library publishers not in the prior two volumes, for a total of 165. Library Publishing Directory 2016, ed. Sarah Lippincott (Atlanta, Ga.: Library Publishing Coalition, 2015).

11. Maria Bonn and Mike Furlough, "The Roots and Branches of Library Publishing Programs," in Bonn and Furlough (2015): 1-13, 10.

12. Library Publishing Coalition, "About Us," available online at http://librarypublishing.org/ about-us [accessed 21 January 2016]. The definition continues: “Generally, library publishing requires a production process, presents original work not previously made available, and applies a level of certification to the content published, whether through peer review or extension of the institutional brand. Based on core library values, and building on the traditional skills of librarians, it is distinguished from other publishing fields by a preference for Open Access dissemination as well as a willingness to embrace informal and experimental forms of scholarly communication and to challenge the status quo." While this definition is broad in some ways, it does seem to exclude digitization efforts, which are covered in other discussions of library publishing introduced in this article.

13. Okerson and Holzman, The Once and Future Publishing Library, 9.

14. The survey and study do not use "library publishers" as the default term because some institutions have been reluctant to describe their services in this way, including some of those described by Bonn and Furlough as offering "libraries and publishing" model. "Library publishing services" stands in as a broader umbrella term to include the full range of models suggested by LPC.

15. Jingfeng Xia, “Library Publishing as a New Model of Scholarly Communication," Journal of Scholarly Publishing 40, no. 4 (2009): 370-83, 372; Isaac Gilman, Library Scholarly Communication Programs: Legal and Ethical Considerations (Oxford: Chandos Publishing, 2013).

16. Tracy, "The Users of Library Publishing Services" (2015).

17. Brown, Griffiths, Rascoff, and Guthrie, University Publishing in a Digital Age, 36.

18. Tracy, "The Users of Library Publishing Services" (2015). For further analysis of these statements, see Daniel G. Tracy, "Topics and Trends in Library Publishing Mission Statements," Poster at Library Publishing Forum 2015, Portland, Ore., March 29, 2015, available online at http:// hdl.handle.net/2142/74838 [accessed 2 September 2015].

19. Digital Library Federation Assessment Interest Group User Studies Working Group, Surveying the Landscape: Use and Usability Assessment of Digital Libraries, December 2015, available online at https://docs.google.com/document/d/1i9x1Su48KWBU14I0i5odrxh1SCYurrGWLXlfiST 5NLI/edit?usp=sharing [accessed 24 January 2016].

20. Rebecca Kennison, Neni Panourgiá, and Helen Tartar, "Dangerous Citizens Online: A Case Study of an Author-Press-Library Partnership," Serials 23, no. 2 (2010): 145-49, doi:http://dx.doi. org/10.1629/231456.

21. Nancy L. Eaton, Bonnie MacEwan, and Peter J. Potter, “Learning to Work Together: The Libraries and the University Press at Penn State," Journal of Scholarly Publishing 35, no. 4 (2004), 215-20, doi:http://dx.doi.org/10.1353/scp.2004.0020.

22. Patrick Alexander, James McCoy, Leila Salisbury, and Richard Brown, "Mixing Oil and 
Water: Recipes for Press-Library Collaboration," Proceedings of the Charleston Library Conference, 2011: 413-17, 416, doi:http://dx.doi.org/10.5703/1288284314937.

23. For a recent literature review of library e-book user studies that exposes the tip of the iceberg, see Michael Lamagna, Sarah Hartman-Caverly, and Erica Swenson Danowitz, "Integrating e-Books into Academic Libraries: A Literature Review," Internet Reference Services Quarterly 20, no. 1/2 (2015): 19-32, doi:http://dx.doi.org/10.1080/10875301.2015.104939. For an extended analysis of various types of reading and the characteristics of academic reading in particular, see Terje Hillesund, "Digital Reading Space: How Expert Readers Handle Books, the Web, and Electronic Paper," First Monday 15, no. 4/5 (2010), available online at http://firstmonday.org/ojs/index.php/ fm/article/view/2762/2504 [accessed 13 December 2016].

24. Relevant examples include: Nicholas Chen, Francois Guimbretiere, and Abigail Sellen, "Designing a Multi-Slate Reading Environment to Support Active Reading Activities," ACM Transactions on Computer-Human Interaction 19, no. 3 (2012), doi:http://dx.doi.org/10.1145/2362364.2362366; Juliane Franze, Kim Marriott, and Michael Wybrow, “Does a Split-View Aid Navigation Within Academic Documents?" in Proceedings of the 2015 ACM Symposium on Document Engineering (New York: ACM, 2015): 211-14, doi:http://dx.doi.org/10.1145/2682571.2797093; Jennifer Pearson, George Buchanan, Harold Thimbleby, and Matt Jones, "The Digital Reading Desk: A Lightweight Approach to Digital Note-Taking," Interacting with Computers 24, no. 5 (2012):327-38, doi:http:// dx.doi.org/10.1016/j.intcom.2012.03.001; Hirohito Shibata, Kentaro Takano, and Shun'ichi Tano, "Text Touching Effects in Active Reading: The Impact of the Use of a Touch-Based Tablet Device," in Human-Computer Interaction - INTERACT 2015: 15th IFIP TC 13 International Conference, Bamberg, Germany, September 14-18, 2015, Proceedings, Part I, eds. Julio Abascal, Simone Barbosa, Mirko Fetter, Tom Gross, Philippe Palanque, and Marco Winckler (Cham: Springer, 2015): 559-76, doi:http://dx.doi.org/10.1007/978-3-319-22701-6_41.

25. Melanie Schlosser, "Access/ibility in Digital Publishing: Summer Seminar at WVU," The Lib Pub: a Group Blog on Library Publishing (July 15, 2015), available online at https://librarypublishing. wordpress.com/2015/07/15/accessibility-in-digital-publishing-summer-seminar-at-wvu/ [accessed 13 December 2016].

26. Laurie Borchard, Michael Biondo, Stephen Kutay, David Morck, and Andrew Philip Weiss, "Making Journals Accessible Front \& Back: Examining Open Journal Systems at CSU Northridge," OCLC Systems \& Services 31, no. 1 (2015): 35-50. They did, however, note the back end for authors and editors would "pose some problems for users with disabilities" (49).

27. Amy Buckland, "More than Consumers: Students as Content Creators," in Bonn and Furlough (2015): 193-202.

28. Association of College and Research Libraries, Working Group on Intersections of Scholarly Communication and Information Literacy, Intersections of Scholarly Communication and Information Literacy: Creating Strategic Collaborations for a Changing Academic Environment (Chicago: Association of College and Research Libraries, 2013), available online at http://acrl.ala.org/intersections/ [accessed 13 December 2016]; Common Ground at the Nexus of Information Literacy and Scholarly Communication, eds. Stephanie Davis-Kahl and Merinda Kaye Hensley (Chicago: Association of College and Research Libraries, 2013).

29. The enhanced data set is openly available under a CC0 license through the Illinois Data Bank. Under the repository agreement, the data set will be preserved for five years, at which point it will be reassessed for continued need. The data set is available at https://doi.org/10.13012/ B2IDB-1968634_V1.

30. OpenDOAR, the Directory of Open Access Repositories, lists 2,525 institutional repositories worldwide, far more institutions than listed in the LPC's directory regardless of extent of services. "Open Access Repository Types-Worldwide" (chart), available online at www.opendoar.org/ about.html\#scope [accessed 24 January 2016]. While it is possible that many of these repositories do not meet the LPC definition of library publishing, the large number suggests the likelihood of significant gap in the directory's coverage of deposit-based library publishing services to begin with, a gap that could stem from lack of awareness of the directory as well as disagreement over whether the term "publishing" applies to items such as ETDs.

31. Joyce Ogburn, "Closing the Gap between Information Literacy and Scholarly Communication," in Davis-Kahl and Hensley, v-viii. 